\title{
A different aspect of the unexpected death of Mozart at the age of 35 years
}

\author{
Ayhan Kanat, ${ }^{\prime *}$ (๑) Elena Romana Gasenzer, ${ }^{2}$ and Edmund Neugebauer ${ }^{3}$
}

\footnotetext{
${ }^{1}$ Medical Faculty, Department of Neurosurgery, Recep Tayyip Erdogan University, Rize, Turkey

${ }^{2}$ Faculty of Health, Department of Medicine, Witten/Herdecke University, Campus Köln-Merheim, Institute for Research in Operative Medicine, Köln, Germany

${ }^{3}$ President of Brandenburg Medical School - Theodor Fontane, Campus Neuruppin, Germany and Senior Professor of Health Services Research at Witten/Herdecke University, Germany
}

The cause of the early death of Wolfgang Amadeus Mozart (1756-1791) at the age of 35 has been the source of much discussion in the medical community. Investigators attributed to Mozart nearly 150 different medical diagnoses. However, the neurosurgical aspect of the early death of Mozart has yet to be well-analyzed, and this subject was investigated herein. The key words "Mozart" and "Mozart's death" were searched in PubMed as well as the libraries of universities. The main source was the archive and website of Internationale Stiftung MOZARTEUM/Salzburg (www.mozarteum.at) and the cranium stored in the Internationale Stiftung Mozarteum in Salzburg/ Austria. The linear fracture of the cranium is important, since it shows the neurosurgical aspect of the early death of Mozart. Mozart's disease was most likely a neurotraumatologic one. His fracture likely occurred several months before his death, as evidenced by signs of healing. Intense headaches and declining musical performance in his last year may have been influenced by intracranial hemorrhage induced by the linear fracture. His final disease therefore may have been chronic postconcussion syndrome depending on chronic calcified epidural hematoma.

Received 1 December 2018; Accepted 5 December 2018; First published 23 April 2019

Key words: Mozart, skull fracture, traumatic brain injury, chronic epidural hematoma, history.

\section{Introduction}

The brain is the locus of memory, compassion, logic, identity, and art. ${ }^{1,2}$ Some studies have reported that Wolfgang Amadeus Mozart's music has positive effects on brain functions, a theory known as the Mozart effect. ${ }^{1,3}$ Mozart (born Johannes Chrysostomus Wolfgangus Theophilus Mozart) is one of the most famous composers of classical music, born in Salzburg on January 27, $1756 .{ }^{4}$ He died at the age of 35 after suffering for 14 days from an acute and mysterious illness. In the medical community, there is still an interest in the exact cause of his early and unexpected death; multiple hypotheses have been formulated to explain the exact nature of Mozart's last illness, and investigators have attributed nearly 150 different medical diagnoses to him. ${ }^{5-7}$ All suggestions remain unproven. Since 1902 the "Internationale Stiftung Mozarteum" has owned a cranium assumed to be that of Mozart. ${ }^{5}$ The temporoparietal fracture on

*Address correspondence to: Ayhan Kanat, MD, Medical Faculty, Department of Neurosurgery, Recep Tayyip Erdogan University, 53100 Merkez, Rize, Turkey.

(Email: ayhankanat@yahoo.com)
Mozart's skull has led to speculations about the possibility of a neurological disease as a cause of his early death, but the neurosurgical aspect of his death has not been well-analyzed. In this study, we searched the cause of neurosurgical aspects of the early death of Mozart.

\section{The Last Disease of Mozart}

Between 1780 and 1790 Mozart completed almost 300 compositions, and he had no serious illnesses until he was 28 years old. ${ }^{1}$ In July 1789, however, when he was 33 , he began to complain of an intermittent headache and toothache. ${ }^{8}$ In 1791, the last year of Mozart's life, he was especially prolific, up to his final months: the special and ingenious opera composition, "Titus," which he completed on September 5 and conducted himself; the magnificent "Magic Flute," the premiere of which he performed on September 30; the clarinet concerto "Freemason's Cantata," which he performed on November 18; and his famous Requiem, which he worked on up to his last moments and could not complete. In a letter to his friend Da Ponte, in September 1791, he wrote "My head is lost (ho il cape frastomato), I am completely exhausted and 

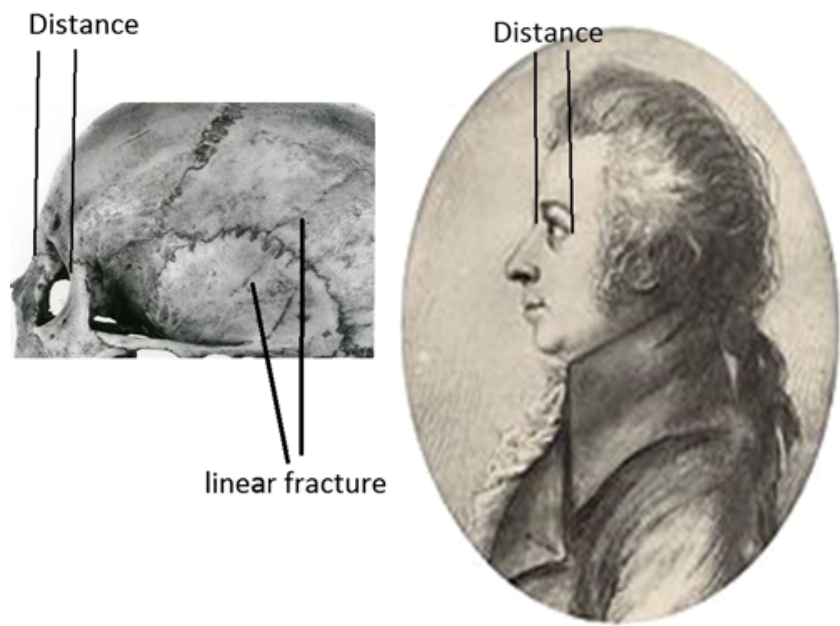

FIGURE 1. In relation to the portrait by Dorothea Stock from 1789, there are similarities between the skull and the portrait. The left side fracture is seen.

cannot take my eyes off the image of this stranger. I no longer have to tremble; I can feel something that proves the hour of my death is striking; I am close to death."8

\section{Mozart's Untimely Death and the Review of his Skull}

There are speculations on neurosurgical pathology as a cause of Mozart's early death. ${ }^{6,8,9}$ Eyewitness accounts, such as his wife's, Constanze, recorded his symptoms and final hours. Just 15 days after the onset of his illness, Mozart went into convulsions, lapsed into a coma, and died. Upon his death, Constanze crawled into bed with the corpse and clutched it.

On November 20, two days after the world premiere of the "Freemason's Cantata," Mozart became ill and developed fears of death, suffering from bad headaches and vomiting. After a week, half of his body was paralyzed. Mozart became bedridden on November 22, $1791^{1}$ and never rose from it again. His physicians were unable to correctly diagnose him. G. M. Nissen ${ }^{10}$ wrote in his biography on Mozart, "Accordingly, the family doctor Dr. Closset, who arrived on the last evening of his life, Mozart fell unconscious, from which he did not come to himself again." On December 5, at midnight, he suddenly stretched on his bed and bent his head toward the wall, then fell into a comatose state. Fifty-five minutes later, he was dead. ${ }^{8,11}$ Mozart was acutely ill only 14 days: he wrote his Requiem up until a few hours before his death, he was awake and cooperative until December 4, and unconsciousness suddenly occurred only two hours before his death.

Mozart was entombed in a common grave at the Vienna cemetery of St. Marx..$^{5}$ The "Mozart cranium" was a dubious relic - in 1842 grave-diggers from the St. Marx cemetery found a skull on a place where
Mozart could be buried. ${ }^{12,13}$ The skull was transferred to the bone collection of Joseph Hyrtl, ${ }^{5}$ a famous anatomist from the University of Vienna, who believed it to be the skull of Mozart. ${ }^{8}$ The cranium was finally given to the Stiftung Mozarteum in 1902. ${ }^{5}$ However, it has not been unequivocally confirmed that the described skull was of Mozart. $^{12}$

The examined skull, though, could be that of Mozart. The age of the person whose skull was discovered was expected to be over 25 but not older than 40. In relation to the portrait of Mozart by Dorothea Stock from 1789 , there are similarities between the skull and the portrait, especially in relation to the lateral view of the skull (see Figure 1). ${ }^{12}$ The skull shows a fracture (a break, or crack of the bones) on the left temporoparietal region with some healing. We believe his right side was paralyzed because the fracture of the cranium was on the left side (as seen in Figure 1).

\section{Neurosurgical Aspects of Differential Diagnosis}

\section{Head injury and skull fracture}

Mozart may have suffered head trauma at the age of 35 prior to his death, as his skull showed a big fracture on the left temporoparietal region with clear signs of healing. ${ }^{14}$ This healed fracture line was very thin, with a little irregular run. The whole fracture line on the outer left side of the skull was nearly $10 \mathrm{~cm}$ long and reached from the left parietal eminence to the base at the parietotemporal junction. No osseous displacement was seen. ${ }^{14}$ The inner side of the left temporal and parietal bones, on the calvarial surface, showed an explicit imprint of a calcified epidural hematoma, with a size of about $45 \mathrm{~cm}^{2}{ }^{14}$ However, the fracture line was in accordance to the outer side a little bit displaced, and the surface of lamina interna was considerably altered 
about an area of $8 \times 5 \mathrm{~cm}^{2} .{ }^{14}$ This type of fracture may have been the consequence of a fall. Kritscher and Szilvássy concluded in 1990 that the fracture may have occurred before the person was an adult. ${ }^{13}$ A mapping of the CT performed at the Natural History Museum was requested, but could not be obtained. We could not agree, however, with Kritscher about the date of fracture of Mozart and believe that the trauma and fracture of Mozart's skull occurred nearer to his death. After a traumatic brain injury (TBI), impairments in physical, cognitive, psychological, and behavioral functioning are common. ${ }^{15}$ Mozart was 34 years when he suffered a likely TBI. Diagnosing a TBI is primarily performed by radiological examination, which was not possible during the times of Mozart.

\section{Chronic subdural hematoma}

Chronic subdural hematoma (CSH) is one of the most frequent types of post-traumatic disease ${ }^{16}$ in neurosurgery among the elderly. ${ }^{17}$ It often manifests with headaches and insidious loss of neurological and cognitive functions. All these symptoms were noted during Mozart's last illness. Calcification of CSH is found in $0.3-2.7 \%$ of CSH cases and generally found in children and young adults, ${ }^{18}$ as was likely seen in Mozart at the age of 35 .

\section{Epidural hematoma}

Epidural hematoma may occasionally develop slowly, which likely occurred in Mozart's cranium. This type of epidural hematoma is a distinct and rare entity. This situation may also explain his severe headache during his last year. The last disease of Mozart may have had an effect on the composition of his K.626 Requiem and perhaps other last works. ${ }^{19}$ However, it should be kept in mind that musical function in professional musicians makes use of both temporal lobes indifferently. ${ }^{20}$ Mozart appears to have survived for a few years, since the fracture was consolidated and epidural hematoma had the time to leave its prints. $^{8}$ Kritscher and Szilvássy described the typical characteristics of an epidural hemorrhage ${ }^{13}$ that occurs by traumatic injury of the middle meningeal artery on the underside of the fracture. In relation to Mozart's neurological state in question, it can be assumed that he might have suffered a chronic calcified epidural hematoma, as argued by Puech et al. ${ }^{8}$ and Drake. ${ }^{19}$

\section{Conclusion}

We thoroughly describe here the neurosurgical aspects of an undoubtedly traumatized skull and open a "way to speculations," but we were unable to definitively clarify the cause of Mozart's death. Historically, we know that Mozart suffered from bad headaches in the spring of
1790 , for more than a year before his death. ${ }^{9}$ We unfortunately don't know about possible major head injuries during his life. A temporoparietal linear fracture on the left side of Mozart's skull is an important neurosurgical aspect in investigating the early death of Mozart. Our assumption is that he fractured his skull several months before his death. Previously, epidural ${ }^{8}$ and chronic subdural hematoma ${ }^{19}$ are reported as occuring during the last illness of Mozart. We think that Mozart suffered a chronic calcified epidural hematoma. Today, neurosurgery has made much progress $;{ }^{21}$ however, during the times of Mozart, it was impossible to make a radiological diagnosis. The early and unexpected death of Mozart was a mystery from the first day, ${ }^{12}$ and in this situation, a final diagnosis of Mozart's brain pathology remains unclear. Some confusion still exists about the exact neurosurgical pathology of Mozart, which cannot be determined without an autopsy report. The speculations, it seems, will continue.

\section{Disclosures}

The authors declare that they have nothing to disclose.

\section{REFERENCES:}

1. Gasenzer ER, Kanat A, Neugebauer E. The unforgettable neurosurgical operations of musicians in the last century. World Neurosurg. 2017; 101(5): 444-450. doi: 10.1016/j.wneu.2016.11.144.

2. Gasenzer ER, Kanat A, Neugebauer E. In reply to "hypothesis on the origin of dance: mirror neuron system and imitation from movement disorders". World Neurosurg. 2018; 120: 605. doi: 10.1016/j.wneu. 2018.09.162.

3. Gasenzer ER, Kanat A, Neugebauer EAM. First report of awake craniotomy of a famous musician: suprasellar tumor surgery of Pianist Clara Haskil in 1942. J Neurol Surg A Cent Eur Neurosurg. 2017; 78(3): 260-268. doi: 10.1055/s-0036-1597895.

4. Wheater M. Mozart's last illness - a medical diagnosis. JR Soc Med. 1990; 83(9): 586-589.

5. Stadlbauer C, Reiter C, Patzak B, et al. History of individuals of the 18th/19th centuries stored in bones, teeth, and hair analyzed by LAICP-MS - a step in attempts to confirm the authenticity of Mozart's skull. Anal Bioanal Chem. 2007; 388(3): 593-602. doi: 10.1007/ s00216-007-1266-3.

6. Ivkic G, Erdeljic V. Could a neurological disease be a part of Mozart's pathography? Coll Antropol. 2011; 35(Suppl 1): 169-173.

7. Karhausen LR. Mozart's 140 causes of death and 27 mental disorders. BMJ. 2010; 341: c6789.

8. Puech B, Puech PF, Dhellemmes P, et al. Did Mozart have a chronic extradural haematoma? Injury. 1989; 20(6): 327-330.

9. Vlcek E, Druga R, Smahel Z, et al. The skull of Wolfgang Amadeus Mozart predicates of his death. Acta Chir Plast. 2006; 48(4): 133-140.

10. von Nissen GN. Biographie W. A. Mozarts. Hildesheim: Georg Olms Verlag; 1984.

11. Breitinger F. Ist es Mozarts Schädel? (1941). In: Kritsher HSJ, ed. Zur Identifizierung Des Mozartschädels. Vienna: Naturhistorisches Musieum Wien; 1990: 9

12. Gasenzer ER, Kanat A, Neugebauer E. Neurosurgery and music effect of Wolfgang Amadeus Mozart. World Neurosurg. 2017; 102: 313-319. doi: 10.1016/j.wneu.2017.02.081. 
13. Kritscher HSJ. Untersuchungen Am Sogenannten Mozart Schädel Durch Die Anthropologische Abteilung Des Naturhistorischen Museums Wien in Den Jahren 1989-1990. In: Kritscher H, Szilvássy J, eds. Zur Identifizierung Des Mozart Schädels. Naturhistorisches Museums; Wien, Austria 1990.

14. Puech PF, Puech B, Tichy G. Identification of the cranium of W.A. Mozart. Forensic Sci Int. 1989; 41(1-2): 101-110.

15. Rydon-Grange M, Coetzer R. What do we know about obsessivecompulsive disorder following traumatic brain injury? CNS Spectr. 2015; 20(5): 463-465. doi: 10.1017/S109285291500053X.

16. Kayaci S, Kanat A, Koksal V, et al. Effect of inner membrane tearing in the treatment of adult chronic subdural hematoma: a comparative study. Neurol Med Chir (Tokyo). 2014; 54(5): 363-373.

17. Kanat A, Kayaci S, Yazar U, et al. Chronic subdural hematoma in adults: why does it occur more often in males than females? Influence of patient's sexual gender on occurrence. J Neurosurg Sci. 2010; 54(3): 99-103.

18. Claiborne JR, Hoge MK, Wood BC, et al. Extradural ossification following epidural hematoma in children: a rare but significant entity. J Craniofac Surg. 2015; 26(5): 1500-1503. doi: 10.1097/ SCS.0000000000001806.

19. Drake MEJ. Mozart's chronic subdural hematoma. Neurology. 1993; 43(11): 2400-2403.

20. Kanat A, Kayaci S, Yazar U, et al. What makes Maurice Ravel's deadly craniotomy interesting? Concerns of one of the most famous craniotomies in history. Acta Neurochir (Wien). 2010; 152(4). doi: 10.1007/s00701-009-0507-y.

21. Gasenzer ER, Kanat A, Ozdemir V, et al. Analyzing of dark past and bright present of neurosurgical history with a picture of musicians. Br J Neurosurg. 2018; 32(3): 303-304. 